

\title{
OASIS URBANO: UNA PROPUESTA DE ACONDICIONAMIENTO TÉRMICO PARA EL METRO DE SANTIAGO
}

\author{
URBAN OASIS: A THERMAL RETROFITTING PROPOSAL FOR THE \\ SANTIAGO METRO
}

\author{
ESTEBAN OMAR BUGUEÑO LARA \\ Magister Integrado en Diseño Arquitectónico \\ Estudiante de Tesis de Magister \\ Universidad de Santiago de Chile, Santiago. Chile \\ https://orcid.org/0000-0001-5627-886X \\ ebuguenolara@gmail.com
}

\section{RESUMEN}

Las estaciones subterráneas del Metro de Santiago pueden llegar a experimentar temperaturas de alrededor de $32^{\circ} \mathrm{C}$ en la zona de andenes durante la época estival, afectando directamente a los usuarios del transporte público. Situaciones similares se repiten en otros sistemas ferroviarios subterráneos del mundo y las soluciones implementadas no han logrado resolver el problema por completo, lo que se traduce incluso en altos costos de operación y mantención. Este trabajo expone una propuesta de acondicionamiento térmico pasivo que toma como caso de estudio la estación Tobalaba L1 del Metro de Santiago. Aprovechando los pozos de ventilación existentes, se simuló un sistema de enfriamiento evaporativo que busca reducir la temperatura al interior de la zona de andenes y, al mismo tiempo, contribuir a reactivar el espacio público en la superficie. La solución propuesta permitió una disminución de la temperatura promedio de $2,5^{\circ} \mathrm{C}$ en verano y $3,6^{\circ} \mathrm{C}$ en invierno, evidenciando que es posible llegar a igualar los alcances de algunas soluciones activas, pero con menores costos involucrados gracias al nulo gasto energético y al aprovechamiento de las preexistencias; y con mejoras en las condiciones del espacio público dada la incorporación del factor cualitativo aportado por la arquitectura.

\section{Palabras clave \\ Climatización, estaciones de subterráneo, espacio público.}

\section{ABSTRACT}

The underground stations of the Santiago Metro can experience temperatures of around $32^{\circ} \mathrm{C}$ in the platform area during the summer season, thereby directly affecting public transport users. Similar situations occur in other subway systems of the world and the solutions implemented have not been able to solve the problem entirely, even resulting in high operating and maintenance costs. This article presents a passive thermal retrofitting proposal that takes the Tobalaba L1 Santiago Metro station as its case study. Taking advantage of the existing ventilation shafts, an evaporative cooling system was simulated that seeks to reduce the temperature in the platform area and at the same time contribute

to reviving the public space on the surface. The proposed solution made it possible to decrease the average temperature $2.5^{\circ} \mathrm{C}$ in the summer and $3.6^{\circ} \mathrm{C}$ in the winter. This demonstrates that it is possible to match the scope of some active solutions, but with lower costs associated with zero energy consumption and the use of existing elements, and with improvements in the conditions of public space by incorporating the qualitative factor from architecture. 


\section{INTRODUCCIÓN}

\section{EL CALOR EN LAS ESTACIONES DEL METRO}

Año tras año, en el Metro de Santiago se repiten escenas de gente abanicándose, sacudiéndose la polera $y$, sobre todo, sudando mucho, producto de las altas temperaturas registradas al interior de las estaciones, principalmente subterráneas, donde se pueden alcanzar temperaturas de alrededor de $32^{\circ} \mathrm{C}$ (Liencura, 2019). Los problemas de calidad ambiental ligados a la temperatura tienen una incidencia variable a lo largo del año, pero comúnmente se asocian al período estival (septiembre a marzo).

Diversas fuentes periodísticas vinculan las altas temperaturas fundamentalmente al tramo central de la línea 1 del Metro (entre Estación Central y Tobalaba), atribuyendo esta situación, por una parte, a "...la mayor afluencia de pasajeros ocasionada por la implementación del Transantiago" ("Instalan megaventiladores", 2010) y, por otra, a "...la mayor frecuencia de trenes que transitan en ese tramo (principal fuente generadora de calor)" (Metro S.A., 2013).

Para el estudio de las cargas térmicas internas en el Metro es importante conocer la situación espacial y temporal de los focos, distinguiendo regiones diferenciadas, que se esquematizan en la Figura 1. Las zonas de andenes y de circulación de los trenes concentran la mayor cantidad de cargas internas, mientras que las zonas de acceso y mezanina se consideran al margen del estudio por contener cargas menos evidentes.

El calor generado por el funcionamiento de los trenes constituye, por lejos, la principal carga existente (92\%), debido primordialmente al sistema de frenado que ocupa cerca de la mitad de la carga térmica interna total. Luego le siguen las instalaciones (6\%) y en menor cantidad los ocupantes (2\%) (Figura 2).

La exposición a ambientes muy calurosos puede derivar en una serie de consecuencias, que afectan por igual a los pasajeros y al personal del Metro. Aquí pueden distinguirse

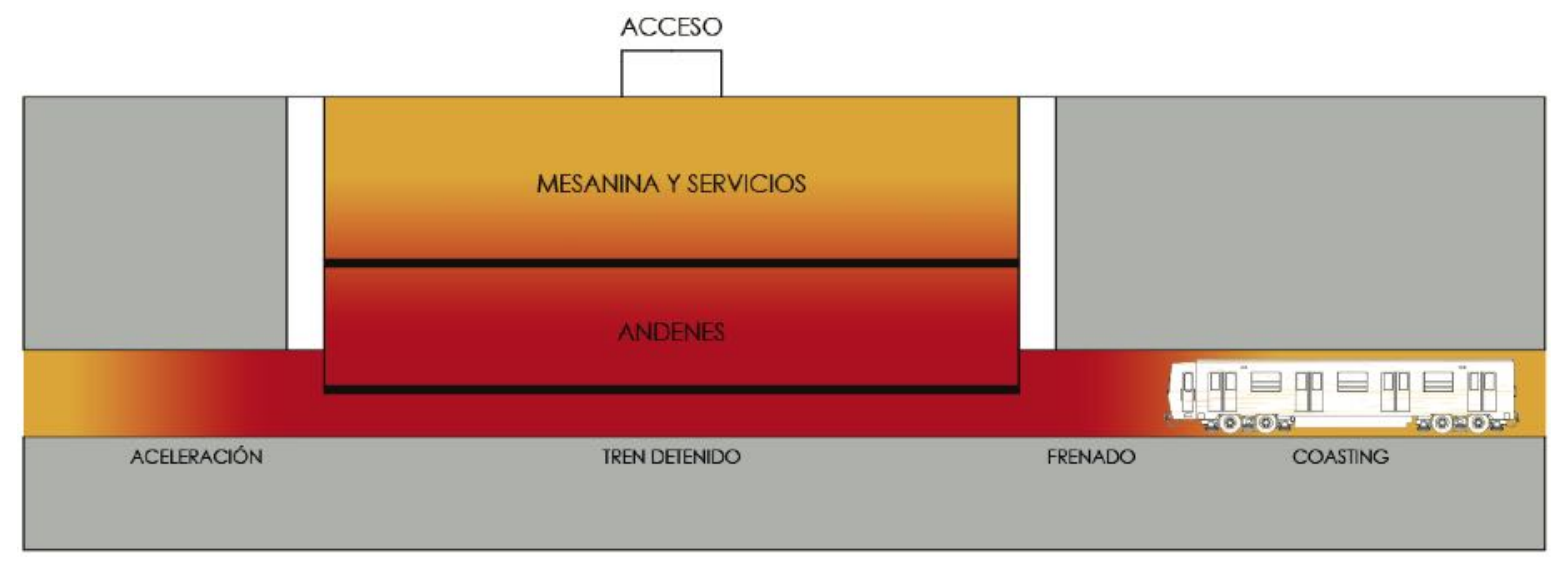

Figura 1. Esquema de cargas térmicas internas. Fuente: Elaboración del autor.

\begin{tabular}{|l|l|c|}
\hline Fuente & Carga térmica & Leyenda \\
\hline \multirow{4}{*}{$\begin{array}{l}\text { Funcionamicnto } \text { de los trenes } \\
\text { Frenado }\end{array}$} & Tracción & \\
\hline & $\begin{array}{l}\text { Fenómenos } \\
\text { aerodinámicos }\end{array}$ & \\
\hline & Contacto rueda-riel & \\
\hline & $\begin{array}{l}\text { Climatización de } \\
\text { trenes }\end{array}$ & \\
\hline \multirow{5}{*}{ Instalaciones } & $\begin{array}{l}\text { Alumbrado y } \\
\text { distribución } \\
\text { eléctrica }\end{array}$ & \\
\hline & Equipamientos & \\
\hline & $\begin{array}{l}\text { Locales } \\
\text { comerciales }\end{array}$ & \\
\hline & $\begin{array}{l}\text { Climatización de } \\
\text { salas técnicas }\end{array}$ & \\
\hline Ocupantes & Calor sensible & \\
\hline & Calor latente & \\
\hline
\end{tabular}

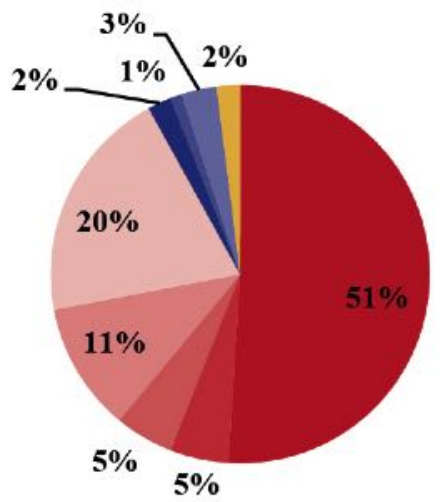


tanto malestares o incomodidades, como afecciones a la salud, en los casos más graves. Además, esto mismo deriva en exclusión social de aquellas personas que puedan ser más vulnerables a los efectos por su condición específica (infantes, adultos mayores, embarazadas, etc.).

\section{MEDIDAS ADOPTADAS FRENTE AL PROBLEMA}

\section{SISTEMA DE VENTILACIÓN PASIVA.}

En las estaciones subterráneas, donde el problema es más crítico, el calor generado debe ser evacuado al exterior del sistema. Los sumideros principales son, en este sentido, la atmósfera y, en menor medida, el terreno circundante. Es por ello que la ventilación se ha convertido en la principal alternativa de enfriamiento, constituyendo un sistema que opera a través de los siguientes componentes:

Pozos de extracción: Se sitúan en las proximidades del punto medio de los tramos del túnel inter-estación y su función es extraer el aire caliente desde el interior (Figura 3).

Pozos de compensación: Se localizan en los piñones de entrada y salida de cada estación. Su función es evitar las molestias de aire generadas por el efecto pistón, fenómeno que ocurre cuando el tren, al circular por el túnel, empuja el aire que se encuentra a su paso de manera que ante este

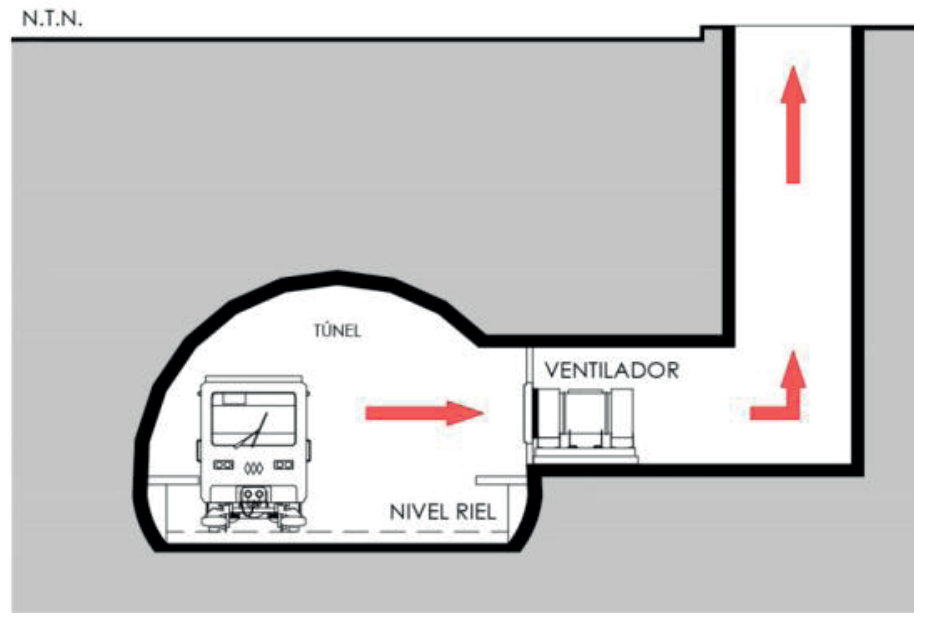

Figura 3. Corte transversal pozos de extracción. Fuente: Elaboración del autor en base a Herrero (2009).

se genera una capa de aire con una presión superior a la normal (Figura 4).

Pozos de inmisión: Se ubican en el andén y a través de ellos se impulsa aire desde el exterior con ayuda de ventiladores con el fin de aumentar las renovaciones de aire. Generalmente, se prescinde de pozos de inmisión (salvo escasas excepciones), cuando, en su lugar, se asocia la entrada de aire desde el exterior a los pozos de compensación en períodos donde no ocurre el efecto pistón (Figura 5).
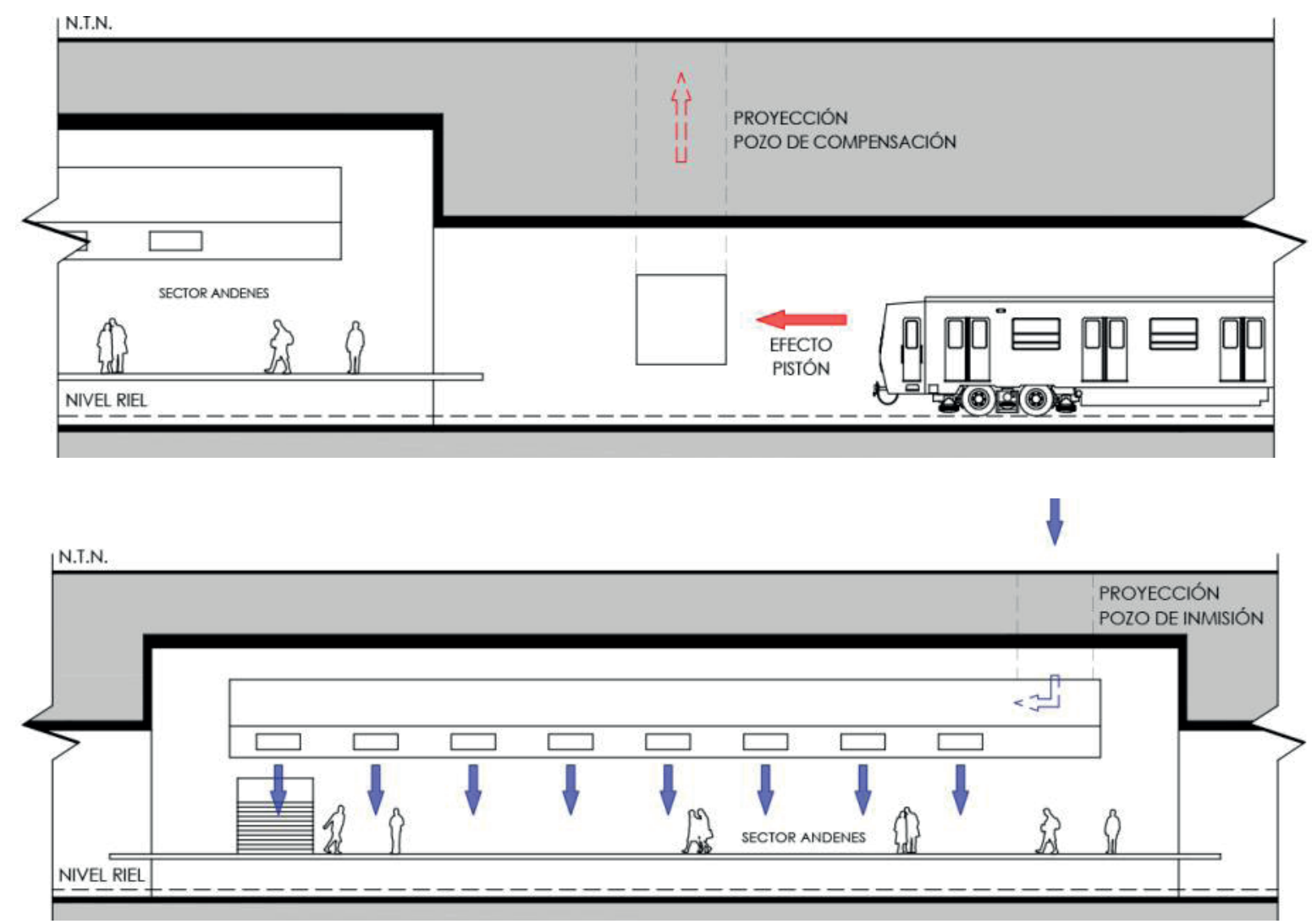


\section{SISTEMA DE VENTILACIÓN ACTIVA}

Como forma de complementar a los sistemas de ventilación pasiva, que no resuelven el problema central, la empresa Metro ha implementado planes de verano que contemplan la incorporación de trenes con aire acondicionado y sistemas de ventilación activa en estaciones, con costos de inversión que solo hasta el año 2010 sobrepasaban los $\$ 2.000 .000 .000$ (Metro S.A., 2010). Concretamente, en la actualidad, el reciente plan de verano 2018-2019 contempló la instalación de 106 megaventiladores en 8 estaciones diferentes, la instalación de puertas con rejillas de ventilación en los coches de las líneas 2 y 5, y la dotación de aire acondicionado para la flota completa de las líneas 1 y 6 ("Con 106 ventiladores", 2018).

La Figura 6 grafica el parque instalado de sistemas de ventilación activo al año 2015 en las estaciones del Metro, donde se advierten los siguientes:

Ventiladores nebulizadores: Equipos de ventilación que utilizan una bomba eléctrica de alta presión y boquillas especiales para enfriar la temperatura del aire, utilizando agua nebulizada.

Ventiladores convencionales: Equipos de ventilación que aumentan el movimiento de las masas de aire en el interior.

Megaventiladores: Sistemas de ventilación industrial que aprovechan el efecto pistón para inducir el movimiento de masas de aire caliente a través del mismo al generar un flujo de aire adicional. Operan mediante celosías y/o ventiladores que pueden ser tanto de inyección como de extracción, dependiendo de las necesidades.

Ventiladores de túnel: Sistemas de ventilación industrial instalados en los pozos de extracción, que tienen como objetivo reforzar la aspiración del aire interior.

\section{SOLUCIONES IMPLEMENTADAS EN OTROS PAÍSES}

\section{ESTACIÓN SÉ, METRO DE SÃO PAULO, BRASIL}

En la estación Sé del Metro de São Paulo se implementaron estrategias de acondicionamiento pasivo donde se ubicaron grandes aberturas hacia la Praça da Sé, un amplio espacio público abierto que incorporó vegetación y espejos de agua. La estrategia buscaba implementar la técnica de enfriamiento evaporativo, mediante la cual el aire que ingresara a la estación disminuyera su temperatura por efecto del agua que aporta el entorno. Sin embargo, dado el clima de São Paulo, caracterizado por la alta presencia de humedad relativa, el enfriamiento evaporativo resultó no ser factible, pues requiere de un clima particularmente seco (Figura 7).

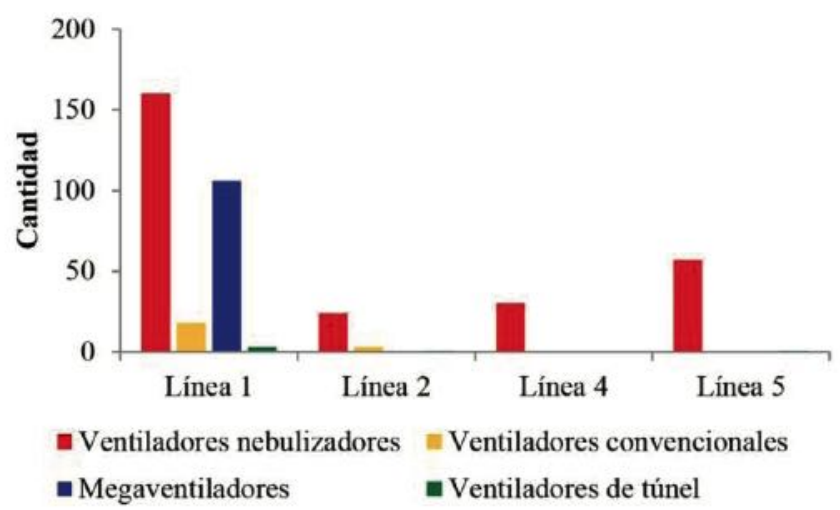

Figura 6. Parque de equipos de ventilación activa por línea. Fuente: Elaboración del autor en base a Metro S.A. (2015).

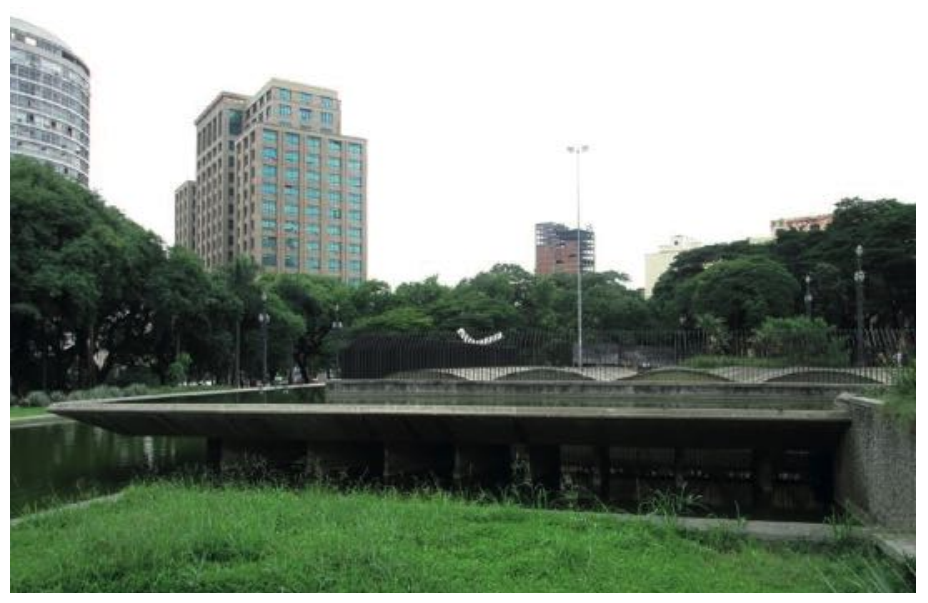

Figura 7. Vinculación entre Praça da Sé y estación Sé. Fuente: Fotografía del autor.

\section{ESTACIÓN PACÍFICO, METRO DE MADRID, ESPAÑA}

En la estación Pacífico del Metro de Madrid se incorporó un sistema geotérmico basado en el aprovechamiento de la temperatura del subsuelo como sistema de climatización. En este se emplea un mecanismo de bomba de calor geotérmico que utiliza el subsuelo, en invierno como fuente de calor, $y$, en verano como disipador del calor, de manera de mantener niveles de temperatura estables todo el año. Dicha bomba se conecta al subsuelo a través de un intercambiador de calor terrestre que permite conducir la carga térmica (Figura 8).

\section{NORTHERN LINE, METRO DE LONDRES, REINO UNIDO}

En la Northern Line del Metro de Londres (London Underground), y teniendo en cuenta el clima oceánico de la ciudad, se aprovecha el calor generado por el sistema para calefaccionar viviendas mediante la incorporación de tubos captadores de aire que desvían el calor a la red de calefacción de la central de energía del Consejo de Bunhill, que a su vez se conecta con cientos de hogares que pueden hacer uso de la energía térmica a través de radiadores (Figura 9). 


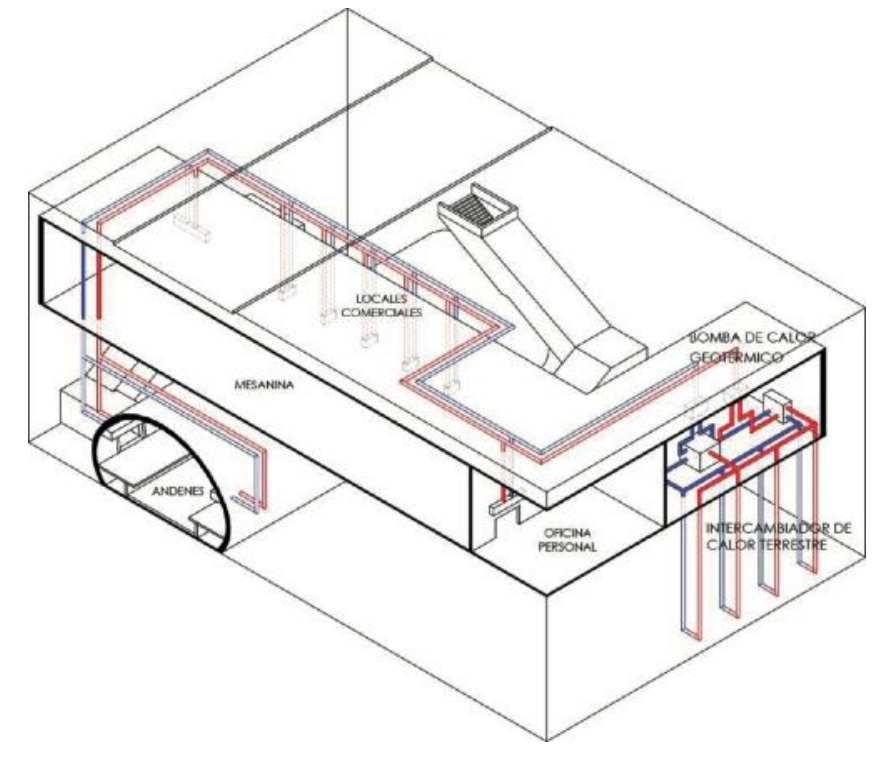

Figura 8. Funcionamiento del sistema geotérmico. Fuente: Elaboración del autor en base a Hendriks, Cubillo y Cuesta (2011).

\section{METODOLOGÍA}

Para el estudio y diagnóstico se decidió trabajar en función de las variables clave del problema: la temperatura ambiental, la ventilación y la humedad del aire. La radiación solar pasa a segundo plano, puesto que en estaciones subterráneas -consideradas la tipología más crítica en este contexto- el problema está ligado fundamentalmente a las cargas térmicas internas.

Con el fin de responder al problema, se determinó un caso de estudio en el que se desarrolló una propuesta de intervención, teniendo como condicionantes el uso de preexistencias y la incorporación de estrategias de acondicionamiento pasivo para alcanzar un diseño replicable y de bajo costo. La alternativa propuesta se sometió a evaluación y análisis en función de lo existente para validar la hipótesis de trabajo.

\section{MEDICIONES EN TERRENO}

Se buscó determinar los niveles de temperatura y humedad al interior de la estación, por medio de registros bisemanales (día laboral y fin de semana) durante 2 semanas cada mes, entre los meses de octubre a marzo. Las mediciones se realizaron en horario punta mañana, horario valle y horario punta tarde, para luego promediar los resultados.

Se utilizó un termómetro ambiental marca EXTECH modelo 44550, considerando un período de aclimatación de 5 minutos para la toma de resultados.

Los datos del clima exterior se obtuvieron de datos del Instituto Metereológico de Noruega (The Norwegian Meteorological Institute, 2016), extrapolados a la ubicación de la estación objeto de estudio, según sus coordenadas.

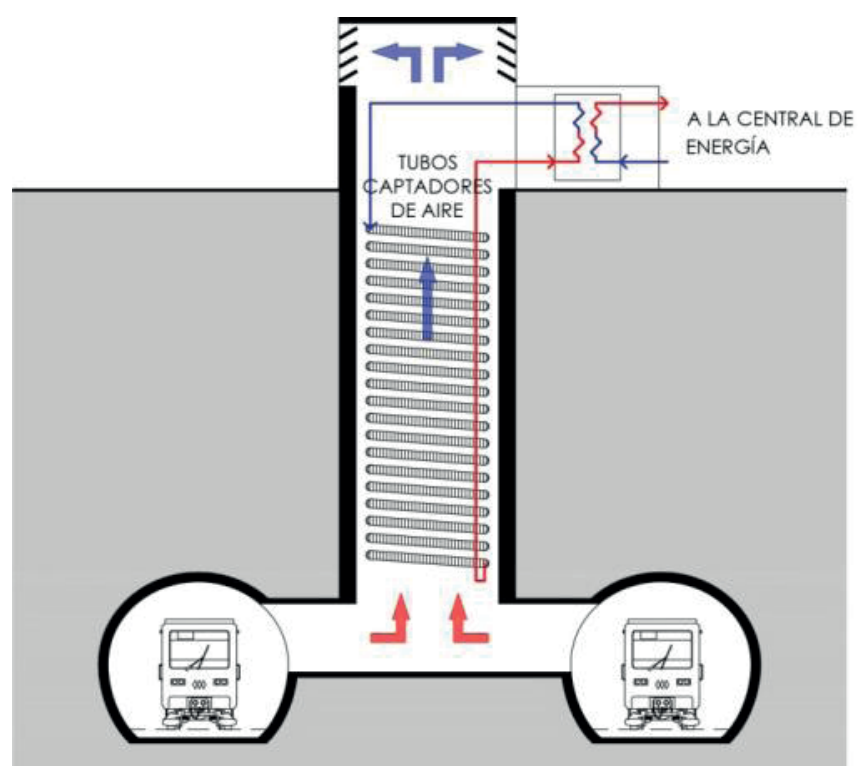

Figura 9. Funcionamiento del sistema de calefacción en la Northern Line. Fuente: Elaboración del autor en base a Arden (2013).

\begin{tabular}{|c|c|c|c|c|c|}
\hline \multirow[b]{2}{*}{ Tipo } & \multirow[b]{2}{*}{ Parámetro } & \multicolumn{4}{|c|}{ Horario } \\
\hline & & Bajo & $\begin{array}{c}\text { Punta } \\
\text { mañana }\end{array}$ & Valle & $\begin{array}{l}\text { Punta } \\
\text { tarde }\end{array}$ \\
\hline \multirow{5}{*}{ Actividad } & $\begin{array}{c}\text { Ocupación } \\
\left(\text { personas } / m^{2}\right)^{1}\end{array}$ & 1,8 & 5,9 & 2,9 & 5,3 \\
\hline & $\begin{array}{c}\text { Tasa metabólica } \\
\text { (W/persona) }\end{array}$ & \multicolumn{4}{|c|}{ De pie, relajado $=1,2$} \\
\hline & $\begin{array}{c}\text { Factor } \\
\text { metabólico }\end{array}$ & \multicolumn{4}{|c|}{0,9} \\
\hline & Vestimenta (clo) & \multicolumn{4}{|c|}{ Invierno $=1,0 /$ Verano $=0,5$} \\
\hline & $\begin{array}{l}\text { Carga térmica } \\
\text { por aparatos y } \\
\text { equipos }\left(\mathrm{W} / \mathrm{m}^{2}\right)\end{array}$ & 225 & 750 & 375 & 675 \\
\hline Cerramientos & $\begin{array}{l}\text { Estructura de } \\
\text { obra gruesa }\end{array}$ & \multicolumn{4}{|c|}{ Hormigón armado } \\
\hline Iluminación & $\begin{array}{l}\text { Tipo de } \\
\text { luminaria }\end{array}$ & \multicolumn{4}{|c|}{ Equipos fluorescentes T8 } \\
\hline
\end{tabular}

${ }^{1}$ Metro S.A., 2007.

${ }^{2}$ American Society of Heating, Refrigerating and AirConditioning Engineers, Inc., 2017.

Tabla 1. Parámetros para la simulación energética del modelo. Fuente: Elaboración del autor en base a las fuentes indicadas.

\section{SIMULACIÓN ENERGÉTICA}

Se llevaron a cabo simulaciones energéticas del modelo en el software DesignBuilder acorde a los parámetros que se resumen en la Tabla 1. 
Según los antecedentes estudiados, se definieron las siguientes instancias de análisis:

6:00 A.M. del 1 de agosto: Horario bajo en día laboral, con el registro de temperaturas más bajas del año (situación en invierno).

18:00 P.M. del 20 de diciembre: Horario punta tarde en día laboral, con el registro de temperaturas más altas del año (situación en verano).

Para determinar la escala de sensación térmica, se recurrió al método Fanger (Fanger, 1973): una herramienta para la valoración del confort térmico en espacios interiores, que contempla diversas variables presentes en los intercambios térmicos persona-ambiente y cuantifica los valores a través de un índice de valoración medio denominado voto medio estimado (PMV) y del porcentaje estimado de insatisfechos (PPD) (Figura 10).

Los resultados arrojados por el software se introdujeron en la herramienta CBE Thermal Confort Tool (Hoyt et al., 2017), la cual se basa en la Norma UNE-EN 15251 que establece una clasificación de los resultados de acuerdo a distintas categorías (Tabla 2).

\section{EVALUACIÓN COSTO/BENEFICIO}

En vista de determinar las ventajas comparativas de la propuesta, estas fueron evaluadas en relación a los principales sistemas de ventilación activa empleados en el Metro de Santiago (megaventiladores y ventiladores nebulizadores), a partir de los siguientes puntos:

1. Costos de inversión.

2. Costos de operación.

3. Costos de mantención.

4. Rango de alcance y unidades por estación.

5. Funcionamiento y efectividad en la reducción de temperatura.

\section{RESULTADOS Y DISCUSIÓN}

\section{IDENTIFICACIÓN DEL CASO DE ESTUDIO}

Como caso de estudio, se determinó trabajar con la estación Tobalaba, al reunir esta la mayor cantidad de condicionantes determinantes del problema:

Ubicación: Se posiciona en el tramo más crítico de la línea 1 , siendo la estación con la mayor afluencia en la red, ya que contempla un estimado de 83.593 pasajeros diarios en días laborales (Herrera, 2018).

Tipología: Corresponde a una estación subterránea, por lo que puede experimentar mayores concentraciones de calor al existir una dificultad en la ventilación desde el exterior. Además, es punto de combinación entre las

\begin{tabular}{|l|l|l|}
\hline PMV & PPD & Sensación \\
\hline 3 & $99 \%$ & Muy caluroso \\
\hline 2 & $77 \%$ & Caluroso \\
\hline 1 & $26 \%$ & Ligeramente caluroso \\
\hline 0 & $5 \%$ & Confort (neutro) \\
\hline-1 & $26 \%$ & Ligeramente frío \\
\hline-2 & $77 \%$ & Frío \\
\hline-3 & $99 \%$ & Muy frío \\
\hline
\end{tabular}

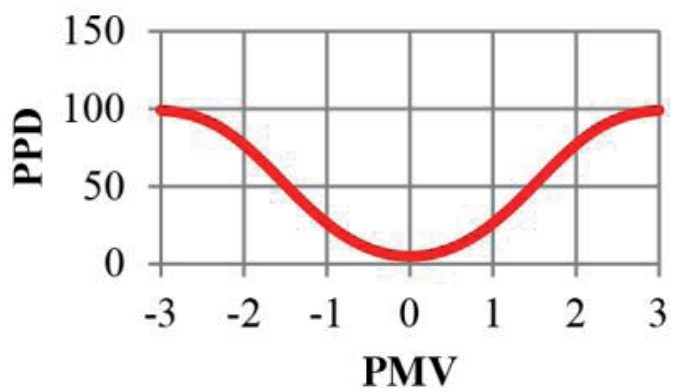

Figura 10. Escala de sensación térmica según método Fanger. Fuente: Elaboración propia en base a Arballo Kuchen, Alamino-Naranjo y Alonso-Frank (2016).

\begin{tabular}{|c|c|c|c|}
\hline Categoría & PPD & PMV & Descripción \\
\hline I & $<6 \%$ & $-0,2$ a $+0,2$ & $\begin{array}{c}\text { Alto nivel de expectativa. } \\
\text { Recomendado para espacios } \\
\text { ocupados por personas } \\
\text { débiles y/o sensibles con } \\
\text { requisitos especiales. }\end{array}$ \\
\hline II & $<10 \%$ & $-0,5 a+0,5$ & $\begin{array}{c}\text { Nivel normal de expectativa. } \\
\text { Debería utilizarse para } \\
\text { edificios nuevos y renovados. }\end{array}$ \\
\hline III & $<15 \%$ & $-0,7 a+0,7$ & $\begin{array}{c}\text { Aceptable y moderado } \\
\text { nivel de expectativa. Puede } \\
\text { utilizarse en edificios ya } \\
\text { existentes. }\end{array}$ \\
\hline IV & $>15 \%$ & $<-0,7$ ó & $\begin{array}{c}\text { Valores fuera de los criterios } \\
\text { de las categorías anteriores. } \\
\text { Esta categoría sólo debería } \\
\text { aceptarse durante una parte } \\
\text { limitada del año. }\end{array}$ \\
\hline
\end{tabular}

Tabla 2. Categorización por niveles de expectativa térmica según norma UNE-EN 15251. Fuente: AENOR, 2008.

líneas 1 y 4, por lo que incide en una mayor afluencia de pasajeros al suplir trayectos en más sentidos y permite estudiar eventuales diferencias de temperaturas entre los andenes de ambas líneas.

Gasto energético: La estación Tobalaba presenta la mayor cantidad de equipos de ventilación activa en la red, entre los cuales la mayor parte corresponde a ventiladores nebulizadores (Metro S.A., 2015). 


\section{PROPUESTA DE INTERVENCIÓN}

La propuesta se desarrolla desde el nivel de superficie mediante la intervención de los pozos de compensación existentes para generar un sistema de enfriamiento evaporativo. Esto, incorporando el concepto de "Oasis Urbano", a través del cual, en analogía a un oasis en el desierto, la iniciativa busca contrastar con el entorno construido y generar un microclima que se convierta en la antesala para la entrada de aire a la estación, el que, una vez acondicionado, será introducido mediante la incorporación de torres de viento que se vincularán con el interior. Al mismo tiempo, se contribuye a reactivar las áreas sobre los pozos de compensación mediante la generación de espacios para la interacción social.

Para efectos del estudio de la propuesta y optimización de los tiempos, se determinó desarrollar una única intervención en el pozo de compensación poniente en la línea 1 (Figuras 11 y 12).

\section{VALIDACIÓN DE LA PROPUESTA MEDICIONES EN TERRENO}

Según esquematiza la Figura 13, la línea 1 de la estación Tobalaba concentra las más altas temperaturas, mientras que hacia la línea 4, a pesar de experimentar diferencias de solo $2,0^{\circ} \mathrm{C}$ con respecto a la anterior, el problema solo es evidente en los momentos más críticos. Ello puede deberse a la menor circulación de trenes hacia la subestación de la línea 4 por ser terminal, en el entendido de que el funcionamiento de los trenes representa el mayor porcentaje de cargas térmicas internas. Por otra parte, la ubicación de la línea 4 a mayor profundidad puede generar una tendencia hacia la estabilidad térmica, sobre todo, considerando su ubicación bajo el canal San Carlos, lo que repercute en una temperatura radiante menor.

Las diferencias de la estación con respecto al exterior pueden alcanzar los $7,9^{\circ} \mathrm{C}$ en promedio, llegando a máximas que bordean los $33^{\circ} \mathrm{C}$, lo que se explica por la nula incidencia de la radiación solar al interior y por la presencia de altas cargas térmicas internas, principalmente en función de la afluencia de pasajeros y la frecuencia de trenes (mayor en horarios punta y días laborales). Mientras tanto, la humedad relativa al interior alcanza niveles muy bajos, en torno al $40 \%$, lo cual obedece más bien a la temperatura, en un sentido inversamente proporcional, y evidencia la sequedad del aire.

\section{SIMULACIÓN ENERGÉTICA}

\section{Clima}

Debido a la amplia oscilación térmica que experimenta Santiago, se perciben grandes diferencias climáticas en invierno y verano. Para el día 20 de diciembre, la temperatura registrada es alta, alcanzado la máxima durante el año, lo

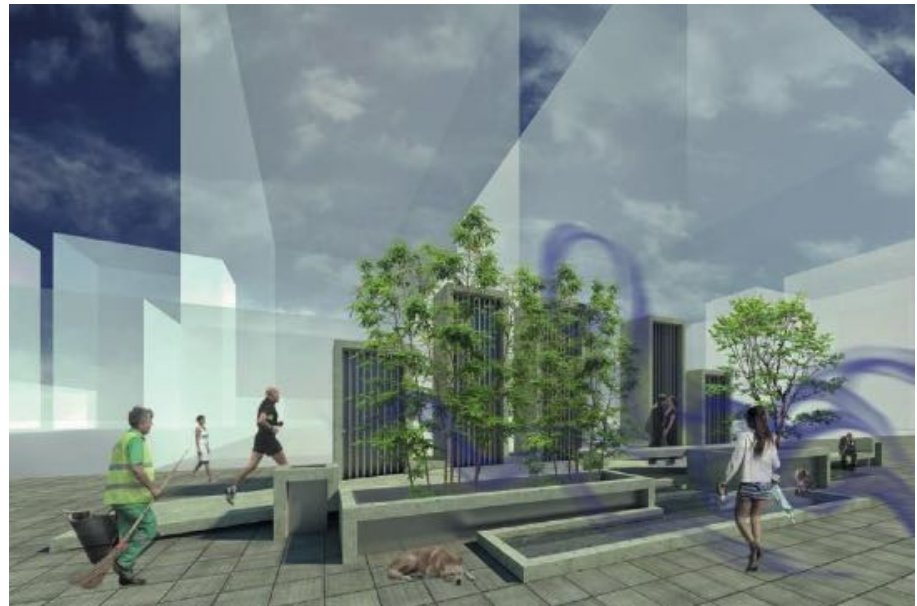

Figura 11. Vista de la propuesta desde vereda sur. Fuente: Elaboración del autor.

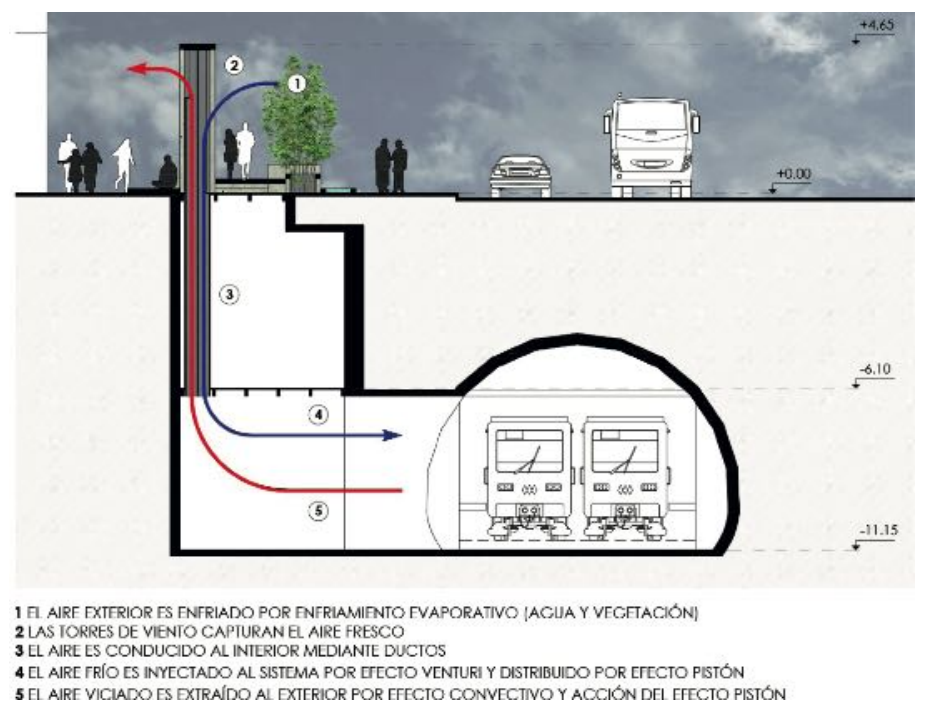

Figura 12. Corte transversal A-A' propuesta. Fuente: Elaboración del autor.

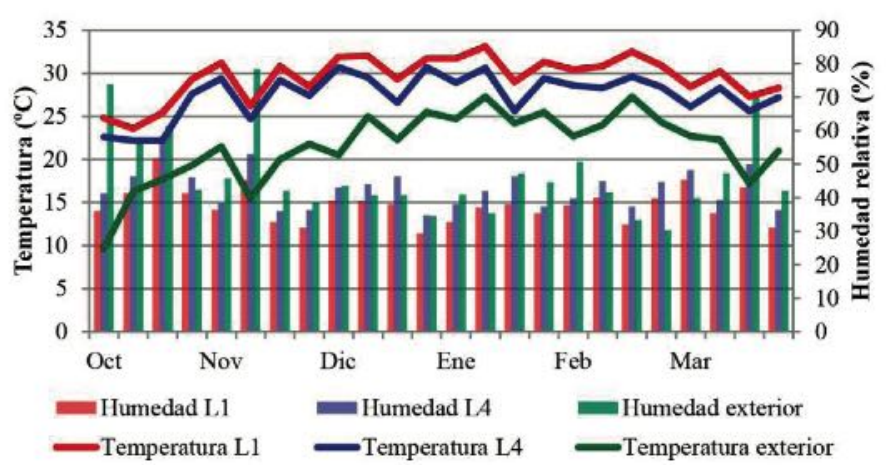

Figura 13. Registros de temperatura y humedad en estación Tobalaba. Fuente: Elaboración del autor. 


\begin{tabular}{|c|c|c|}
\hline \multirow{2}{*}{ Parámetro } & Invierno & Verano \\
\cline { 2 - 3 } & $\mathbf{1}$ de agosto & $\mathbf{2 0}$ de diciembre \\
\cline { 2 - 3 } & $\mathbf{6 : 0 0}$ & $\mathbf{1 8 : 0 0}$ \\
\hline $\begin{array}{c}\text { Temperatura de bulbo } \\
\text { seco }\end{array}$ & $-5,8^{\circ} \mathrm{C}$ & $32,0^{\circ} \mathrm{C}$ \\
\hline $\begin{array}{c}\text { Temperatura de bulbo } \\
\text { húmedo }\end{array}$ & $-5,8^{\circ} \mathrm{C}$ & $18,3^{\circ} \mathrm{C}$ \\
\hline Humedad relativa & $100 \%$ & $26 \%$ \\
\hline Velocidad del viento & $0,0 \mathrm{~m} / \mathrm{s}$ & $4,1 \mathrm{~m} / \mathrm{s}$ \\
\hline Dirección del viento & & Sur $-\mathrm{norte}$ \\
\hline
\end{tabular}

Tabla 3. Parámetros climatológicos promedio para Santiago. Fuente: Elaboración del autor

que se traduce en una baja humedad relativa. Para el día 1 de agosto, en cambio, ocurre la situación a la inversa, registrándose la temperatura más baja del año, con una humedad relativa del $100 \%$, que implica que el vapor de agua que ya no admite el aire se condense en forma de rocío. El comportamiento del viento igualmente varía en ambas situaciones, pero en general la velocidad no es considerable, lo que podría perjudicar las estrategias que contempla la propuesta (Tabla 3).

\section{Estación}

La concentración de altas temperaturas en el andén se da, sobre todo, el día 20 de diciembre, cuando la temperatura del aire alcanza el parámetro más crítico (Tabla 4). Esto es consecuencia directa de las cargas térmicas internas

\begin{tabular}{|c|c|c|c|c|c|}
\hline \multirow{3}{*}{ Parámetro } & \multicolumn{2}{|c|}{$\begin{array}{l}\text { Invierno } \\
1 \text { de agosto }\end{array}$} & \multicolumn{2}{|c|}{20 de diciembre } & \multirow[t]{2}{*}{$\begin{array}{l}\text { Rango } \\
\text { óptimo }\end{array}$} \\
\hline & \multicolumn{2}{|c|}{$6: 00$} & \multicolumn{2}{|c|}{$18: 00$} & \\
\hline & Existente & Propuesta & Existente & Propuesta & $\begin{array}{l}\text { UNE-EN } \\
\text { ISO } 7730\end{array}$ \\
\hline $\begin{array}{c}\text { Temperatura } \\
\text { del aire }\end{array}$ & $28,2^{\circ} \mathrm{C}$ & $24,6^{\circ} \mathrm{C}$ & $34,3^{\circ} \mathrm{C}$ & $31,8^{\circ} \mathrm{C}$ & 10 a $30^{\circ} \mathrm{C}$ \\
\hline $\begin{array}{l}\text { Humedad } \\
\text { relativa }\end{array}$ & $45 \%$ & $45 \%$ & $35 \%$ & $50 \%$ & 30 a $70 \%$ \\
\hline $\begin{array}{l}\text { Velocidad } \\
\text { del aire }\end{array}$ & $0,0 \mathrm{~m} / \mathrm{s}$ & $0,1 \mathrm{~m} / \mathrm{s}$ & $0,0 \mathrm{~m} / \mathrm{s}$ & $0,1 \mathrm{~m} / \mathrm{s}$ & $<1 \mathrm{~m} / \mathrm{s}$ \\
\hline
\end{tabular}

Tabla 4. Resultados de la simulación energética. Fuente: Elaboración del autor en base a AENOR, 2006.

al interior de la estación, que también se acentúan por la nula velocidad del aire más allá de la producida por efectos convectivos. En términos generales, la propuesta no cambia en mayor medida esta situación, pero sí se empieza a evidenciar el ingreso de aire desde el pozo de ventilación, pudiendo aumentarse y llegar a valores más aceptables con el aumento del tiraje en el punto de salida (Figuras 14 y 15).

Cabe mencionar, sin embargo, que no se considera el movimiento de aire asociado a sistemas de ventilación activos ni el flujo de aire inducido por el efecto pistón de los trenes, que puede alcanzar valores cercanos a los $1,8 \mathrm{~m} / \mathrm{s}$ en zonas y momentos muy determinados (Herrero, 2009, p. 79).

\section{SITUACIÓN EN VERANO}

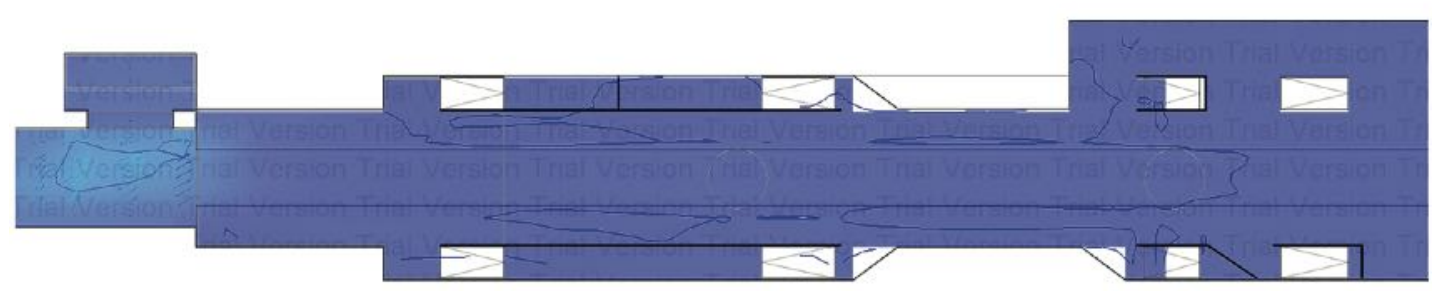

SITUACIÓN EN INVIERNO

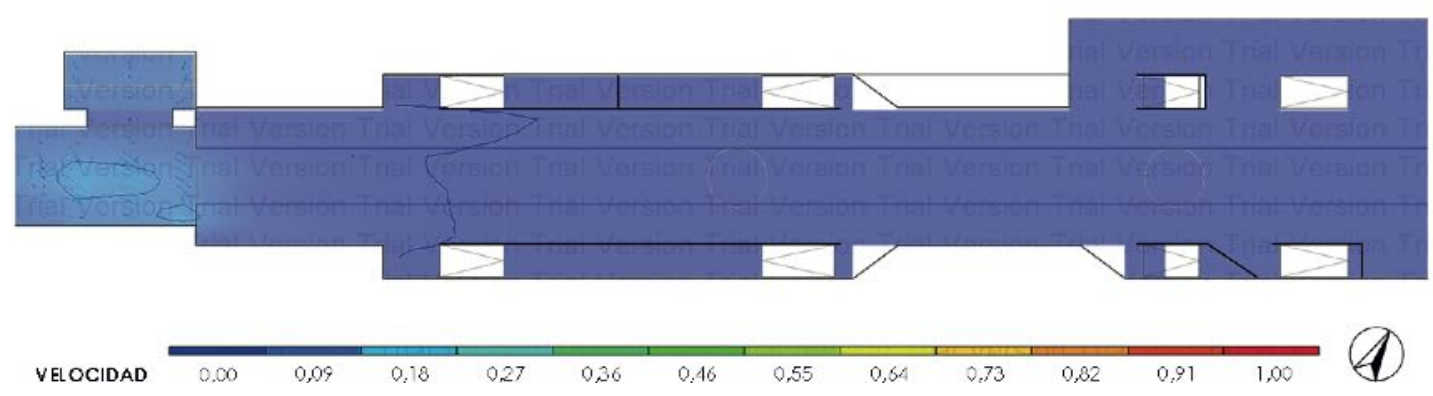


SITUACIÓN EN VERANO

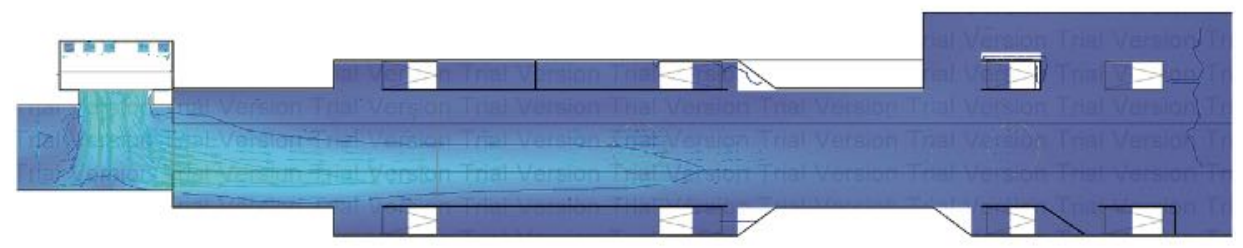

SITUACIÓN EN INVIERNO
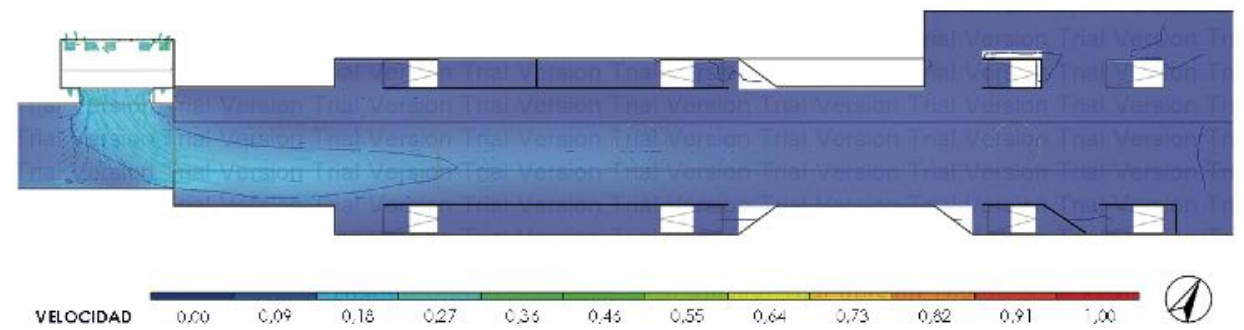

Figura 15. Velocidad del aire para la situación existente. Fuente: Elaboración del autor.T

SITUACIÓN EN VERANO

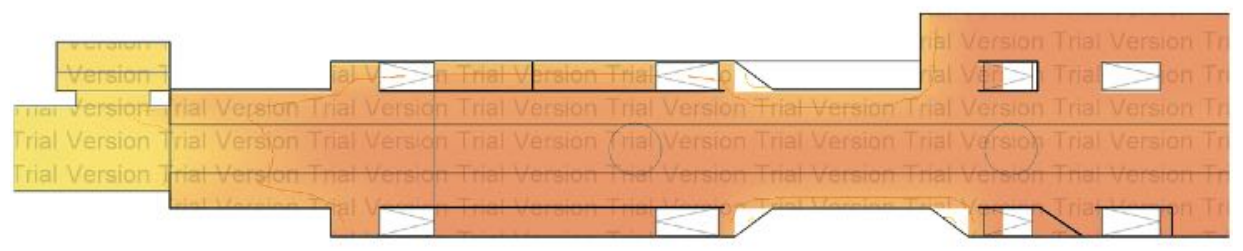

SITUACIÓN EN INVIERNO
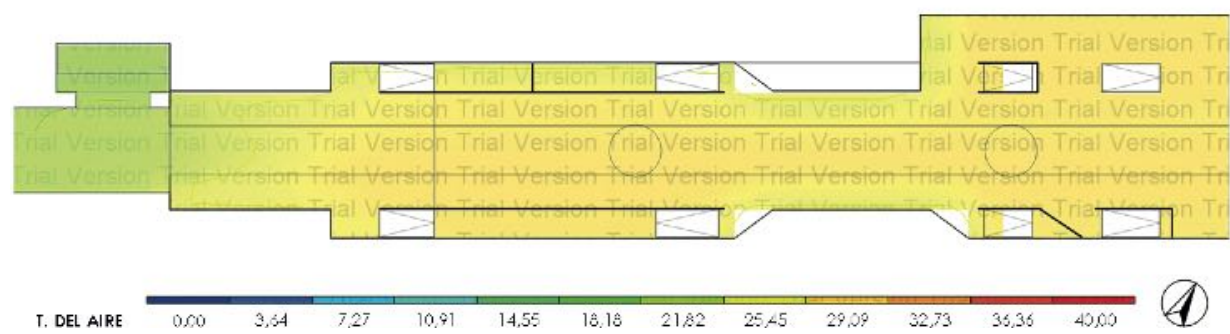

Figura 16. Temperatura del aire para la situación existente. Fuente: Elaboración del autor.

SITUACIÓN EN VERANO

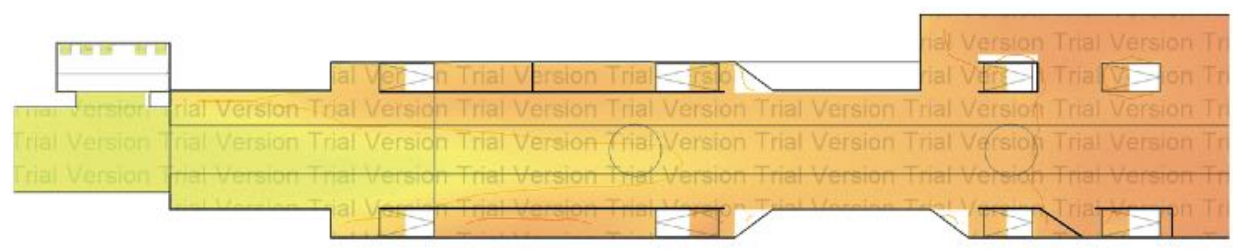

SITUACIÓN EN INVIERNO

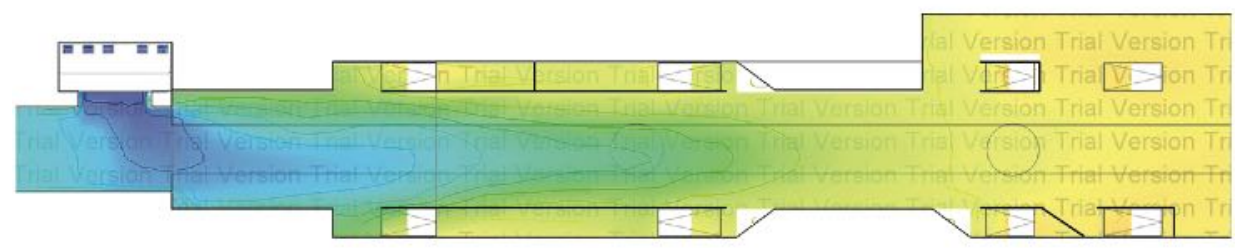

T. DEL AIRE

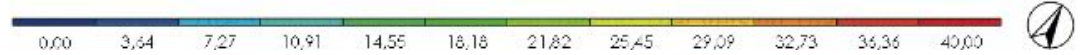

Figura 17. Temperatura del aire para la propuesta. Fuente: Elaboración del autor. 


\begin{tabular}{|c|c|c|c|c|c|c|}
\hline \multirow{4}{*}{ Îndice } & \multirow{2}{*}{\multicolumn{2}{|c|}{$\begin{array}{c}\text { Invierno } \\
1 \text { de agosto }\end{array}$}} & \multirow{2}{*}{\multicolumn{2}{|c|}{$\begin{array}{c}\text { Verano } \\
20 \text { de diciembre }\end{array}$}} & \multirow{3}{*}{\multicolumn{2}{|c|}{ Rango óptimo }} \\
\hline & & & & & & \\
\hline & \multicolumn{2}{|c|}{ 6:00 } & \multicolumn{2}{|c|}{ 18:00 } & & \\
\hline & Existente & Propuesta & Existente & Propuesta & $\begin{array}{c}\text { UNE-EN ISO } \\
7730\end{array}$ & $\begin{array}{c}\text { UNE-EN } \\
15251\end{array}$ \\
\hline PMV & 1,36 & 0,81 & 2,65 & 2,35 & $-2,0 a+2,0$ & $-0,7 a+0,7$ \\
\hline PPD & $44 \%$ & $19 \%$ & $96 \%$ & $90 \%$ & $<77 \%$ & $<15 \%$ \\
\hline Categoría & IV & IV & IV & IV & & | a ||| \\
\hline
\end{tabular}

Tabla 5. Indicadores de sensación térmica. Fuente: Elaboración del autor en base a las fuentes indicadas.

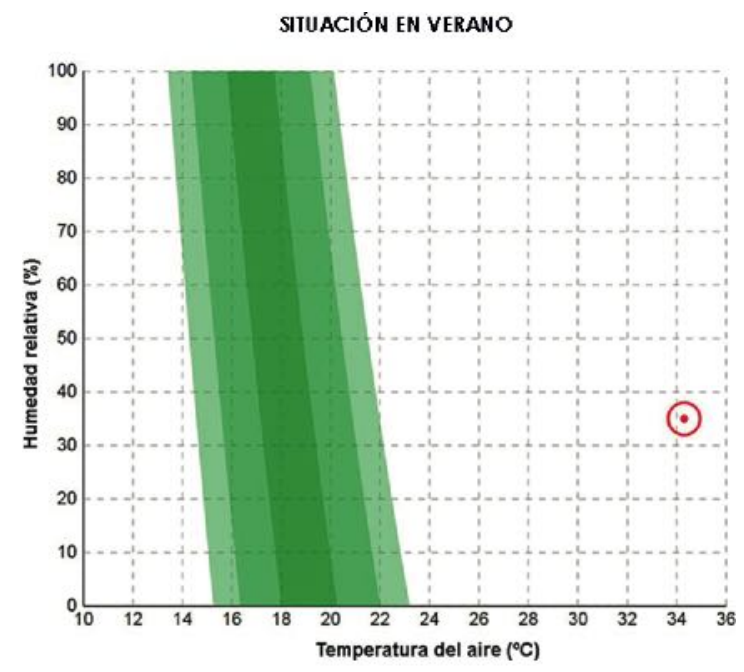

SIUUACIÓN EN INVIERNO

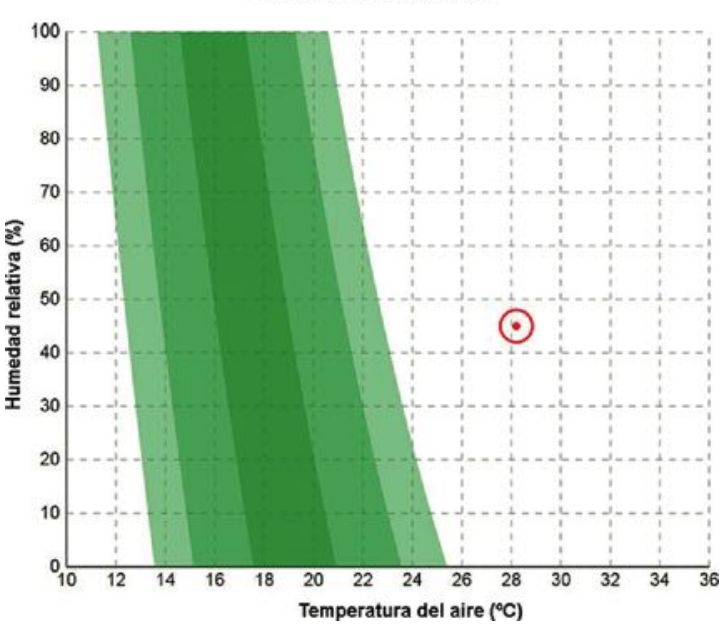

SITUACIÓN EN VERANO

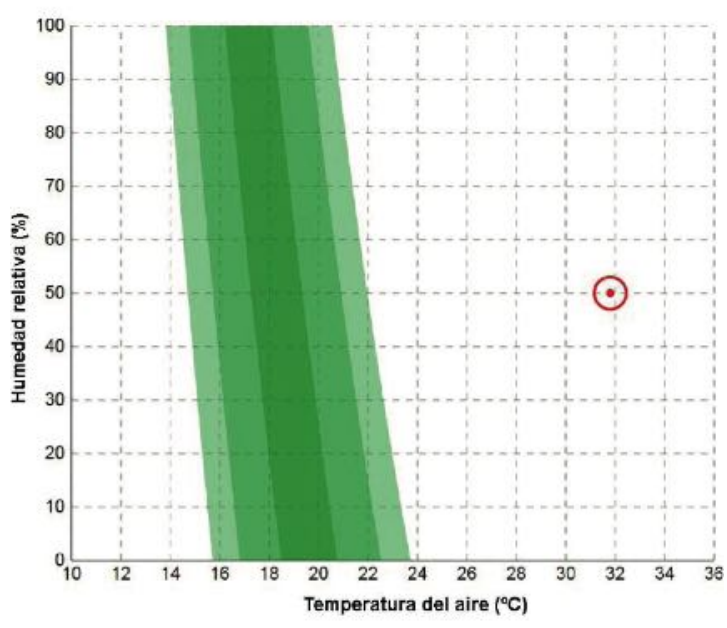

SIIUACIÓN EN INVIERNO

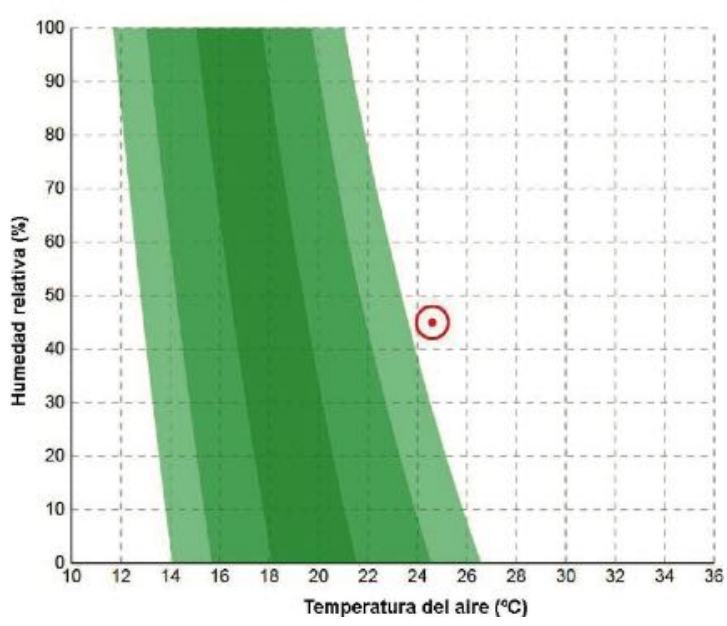

Figura 18. Confort higrotérmico de la situación existente según norma UNE-EN 15251. Fuente: Elaboración del autor en base a Hoyt et al., 2017. Figura 19. Confort higrotérmico de la propuesta según norma UNE-EN 15251. Fuente: Elaboración del autor en base a Hoyt et al., 2017. 
Respecto a la temperatura del aire, la implementación de la propuesta logra una reducción promedio de $3,6^{\circ} \mathrm{C}$ en invierno y $2,5^{\circ} \mathrm{C}$ en verano. Estos valores son incluso más favorables que los obtenidos de las mediciones en terreno para la subestación de la línea 4 donde, a pesar de la escasa diferencia, se percibe ya un cambio considerable.

La humedad relativa al interior es baja para ambas situaciones, lo que garantiza el buen funcionamiento del sistema de enfriamiento evaporativo que, además, contribuye a estabilizar estos valores por efecto de la evaporación del agua y la humidificación del aire.

Los problemas de temperatura se van acentuando, en general, a medida que se toma distancia del pozo de compensación existente, lo que demuestra que, para ambas situaciones, la temperatura producto de las cargas térmicas internas es superior a la temperatura del exterior (Figuras 16 y 17).

Al determinar la escala de sensación térmica por el método Fanger (Tabla 5), se obtienen valores que representan un ambiente muy caluroso $(P M V \approx 3$ ) y caluroso $(P M V \approx 2)$ en verano y un ambiente ligeramente caluroso (PMV $\approx 1$ ) en invierno. Si bien en la práctica durante el invierno podría resultar agradable la estadía en el andén, el método Fanger considera la vestimenta, con el objetivo de determinar un confort tal que no sea necesario variar las prendas de vestir para adecuarse a un determinado ambiente.

La propuesta, si bien mantiene valores similares, logra disminuir el porcentaje estimado de insatisfechos en la zona de andenes en 6\%, al 20 de diciembre, y en 25\%, al 1 de agosto, clasificándose, por tanto, en la categoría IV que es aceptable solo para los períodos más críticos.

Si estos los valores se adecúan a la norma UNE-EN ISO 7730, en ninguno de los dos casos se cumpliría con esta para el día 20 de diciembre, mientras que al día 1 de agosto la situación sería favorable. Sin embargo, la norma UNE-EN 15251, siendo más precisa, determina valores fuera del confort para ambas situaciones, aunque de cualquier forma el escenario crítico se sitúa en verano.

Las Figuras 18 y 19 permiten determinar los valores de humedad relativa y temperatura del aire que se requerirían bajo el resto de las condiciones registradas según la norma UNE-EN 15251, pudiéndose concluir que, a pesar de las reducciones de temperatura obtenidas con la intervención, sigue sin cumplirse el confort para ambas situaciones. Lo anterior hace necesario reducir la temperatura del aire en alrededor de $10^{\circ} \mathrm{C}$, considerando una humedad relativa entre 30 y 50\% para la situación más desfavorable en verano.

\section{EVALUACIÓN DE LA VIABILIDAD DE LA PROPUESTA}

\section{COSTO}

Según muestra la Tabla 6, referente a los costos de inversión, la propuesta representa la inversión por unidad más alta, pero como solo se requieren dos en estación, la inversión

\begin{tabular}{|c|c|c|c|c|}
\hline & & Megaventiladores & $\begin{array}{c}\text { Ventiladores } \\
\text { nebulizadores }\end{array}$ & Propuesta \\
\hline & $\begin{array}{l}\text { nidades por } \\
\text { estación }\end{array}$ & 2 & 28 & 2 \\
\hline $\begin{array}{l}0 \\
0 \\
0\end{array}$ & $\begin{array}{l}\text { Inversión } \\
(M \$)\end{array}$ & $\begin{array}{l}12.000,0 \mathrm{a} \\
15.000,0^{1}\end{array}$ & $\begin{array}{l}1700,0 \text { a } \\
2000,0^{1}\end{array}$ & 18906,1 \\
\hline 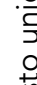 & $\begin{array}{l}\text { Operación } \\
(\mathrm{M} \$)^{3}\end{array}$ & 210 & 70 & \\
\hline U & $\begin{array}{l}\text { Mantención } \\
\text { (M\$) }\end{array}$ & $10.074,5$ & $10.074,5$ & $98,1^{5}$ \\
\hline & $\begin{array}{c}\text { Inversión } \\
(\mathrm{M} \$)\end{array}$ & $\begin{array}{l}24.000,0 \text { a } \\
30.000,0^{1}\end{array}$ & $\begin{array}{l}47600,0^{a} \\
96.000,0^{1}\end{array}$ & $37.812,2$ \\
\hline o & $\begin{array}{l}\text { Operación } \\
(\mathrm{M} \$)^{3}\end{array}$ & 420 & $1.960,00$ & \\
\hline & $\begin{array}{c}\text { Mantención } \\
\text { (M\$) }\end{array}$ & $10.074,5$ & $10.074,5$ & $196,2^{5}$ \\
\hline
\end{tabular}

Metro S.A., 2013.

2 Valor estimado según presupuesto estimado de las obras en base a Ondac, 2018.

${ }^{3}$ Valor estimado considerando un período de funcionamiento de 7 meses (período estival).

${ }^{4}$ Valor estimado según costos estimados de mantención para ventilación activa en base a Instituto Nacional de Estadísticas, 2019.

Valor estimado en base al costo por m2 de área verde para la comuna de Providencia (Guzmán, 2017)

${ }^{*} \mathrm{M} \$=$ Miles de pesos chilenos.

Tabla 6. Costos unitarios y totales para las alternativas analizadas.

Fuente: Elaboración del autor en base a las fuentes indicadas.

total resulta menor a lo contemplado por ventiladores nebulizadores, mas no así por los megaventiladores. Lo anterior se explica por la cantidad de materiales y mano de obra requeridos para la propuesta que, sumado a los tiempos de construcción mayores con respecto a las otras alternativas, puede resultar la opción menos rentable en este punto.

No obstante, en relación a los costos de operación y mantención involucrados, se evidencia que la propuesta constituye la opción más conveniente distando por mucho de las otras alternativas. Esta es una de las principales características de los sistemas de acondicionamiento pasivo, que no requieren personal especializado para su mantenimiento ni consideran gastos por el uso de electricidad. A largo plazo, dichas condiciones determinan la rentabilidad de la propuesta, que se estima podría resultar rentable entre el primer y segundo año de operación, con respecto a los megaventiladores. 


\section{BENEFICIO}

Una vez comparados los atributos asociados a cada alternativa (Tabla 7), se estima que, si bien la propuesta logra por sí sola una menor contribución en cuanto a reducción de temperatura, sus valores podrían igualarse al funcionamiento de los megaventiladores si se consideran 2 unidades por estación, pudiendo la situación ser más favorable o no dependiendo de la zona en que se determine.

Los ventiladores nebulizadores lideran en cuanto a reducción de temperatura se refiere, pero su alcance es muy limitado en comparación a las otras alternativas. Aun así, los modos de funcionamiento de cada alternativa permiten determinar que estas podrían ser complementarias.

Pese a lo anterior, la iniciativa asocia otros beneficios ligados al aporte del espacio público en superficie que pueden favorecer la efectividad de la inversión.

\section{CONCLUSIÓN}

El problema de las altas temperaturas al interior de las estaciones ferroviarias subterráneas, aunque muchas veces resulta no ser un tema prioritario a abordar, conlleva desde afecciones a la salud a exclusión social, en los períodos más críticos, y no solo se presenta en el Metro de Santiago, sino también en sistemas ferroviarios subterráneos de todo el mundo, independiente de las condiciones climáticas. Esto debido a que el problema está ligado a la presencia de altas cargas térmicas internas, principalmente producto del funcionamiento de los trenes, lo que puede derivar en temperaturas de hasta $34^{\circ} \mathrm{C}$ en verano para la zona de andenes.

Las medidas que se han tomado en el Metro de Santiago comprenden el uso de sistemas de ventilación activa que, además de contemplar un alto gasto energético, no han logrado resultados del todo efectivos, lo que lleva a implementar nuevos planes año tras año. En otras partes del mundo la situación es similar, destacándose soluciones basadas en sistemas de acondicionamiento mixto (pasivo y activo), pero que pueden no resultar viables en países que cuentan con recursos más limitados o cuando se tiene en mente otras prioridades. Por ello, la arquitectura tiene mucho que aportar desde la introducción de estrategias de acondicionamiento pasivo y de factores cualitativos que pongan como prioridad al usuario.

La propuesta "Oasis Urbano", si bien no resuelve de lleno el problema, contribuye al demostrar que es posible igualar y/o complementar los alcances de los sistemas activos mediante la implementación de sistemas de acondicionamiento pasivos, teniendo la ventaja de reducir ampliamente los costos de mantención y operación por el nulo gasto energético, y pudiendo reducir los costos de inversión cuando se aprovechan las preexistencias.

\begin{tabular}{|c|c|c|c|c|}
\hline Sistema & $\begin{array}{c}\text { Unidades } \\
\text { por } \\
\text { estación }\end{array}$ & Alcance & $\begin{array}{c}\text { Reducción de } \\
\text { Temperatura } \\
\left({ }^{\circ} \mathrm{C}\right)\end{array}$ & Funcionamiento \\
\hline $\begin{array}{c}\text { Mega } \\
\text { ventiladores }\end{array}$ & 2 & Andén & $\begin{array}{c}3 \text { a } 5 \text { en horario } \\
\text { punta }\end{array}$ & Efecto pistón \\
\hline $\begin{array}{c}\text { Ventiladores } \\
\text { nebulizadores }\end{array}$ & 28 & $\begin{array}{c}\text { Hasta 2 } \\
\text { metros en } \\
\text { andén }\end{array}$ & 6 por unidad & Agua nebulizada \\
\hline Propuesta & 2 & Andén & $\begin{array}{c}\text { Alrededor de 3 } \\
\text { por unidad }\end{array}$ & $\begin{array}{c}\text { Ingreso de aire } \\
\text { fresco }\end{array}$ \\
\hline
\end{tabular}

Tabla 7. Eficacia de las alternativas analizadas. Fuente: Elaboración del autor en base a Metro S.A., 2010.

En este punto, el aprovechamiento de los pozos de compensación existentes le otorga a la propuesta una doble funcionalidad, al permitir aportar al espacio público en superficie mediante espacios basados en la versatilidad y ambigüedad espacial.

\section{AGRADECIMIENTOS}

Agradezco al profesor Mg. Arquitecto Rodrigo Aguilar de la Universidad de Santiago de Chile, por su constante apoyo y guía durante el desarrollo de este trabajo.

\section{REFERENCIAS BIBLIOGRÁFICAS}

AENOR (2006). Ergonomía del ambiente térmico. Determinación analítica e interpretación del bienestar térmico mediante el cálculo de los índices PMV y PPD y los criterios de bienestar térmico local (ISO 7730:2005). UNE-EN ISO 7730:2006. Madrid: AENOR.

AENOR (2008). Parámetros del ambiente interior a considerar para el diseño y la evaluación de la eficiencia energética de edificios incluyendo la calidad del aire interior, condiciones térmicas, iluminación y ruido. UNE-EN 15251:2008. Madrid: AENOR.

AMERICAN SOCIETY OF HEATING, REFRIGERATING AND AIRCONDITIONING ENGINEERS, INC. (2017). AHSRAE Handbook Fundamentals. Atlanta: ASHRAE.

Arballo, B., Kuchen, E., Alamino-Naranjo, Y. y Alonso-Frank, A. (2016). Evaluación de Modelos de Confort Térmico para Interiores. En: VIII Congreso Regional de Tecnología de la Arquitectura CRETA, Universidad Nacional de San Juan, Islas Malvinas.

Arden, C. (2013). London underground tunnels to heat homes. Islington now. Recuperado de http://islingtonnow.co.uk/londonunderground-tunnels-to-heat-homes/. 
Con 106 ventiladores gigantes en 8 estaciones Metro capeará el calor (2018). La Hora. Recuperado de http://www.lahora. cl/2018/11/106-ventiladores-gigantes-8-estaciones-metrocapeara-calor/.

Fanger, P. O. (1973). Thermal Comfort. New York: McGraw-Hill Book Company.

Guzmán, J. M. (2017). La Gestión Municipal de áreas verdes en el gran Santiago. Santiago: Fundación Mi Parque.

Hendriks, M., Cubillo, J. M. y Cuesta, M. (2011). Refrigeración del Metro con Geotermia. Retos y experiencias de un caso real: Metro Madrid - Estación Pacífico. El Instalador, (482), 118-126.

Herrera, J. (2018). Tobalaba, Manquehue y La Cisterna son las estaciones de metro con mayor afluencia. El Mercurio recuperado de https://gobierno.udd.cl/cpp/noticias/2018/07/03/tobalabamanquehue-y-la-cisterna-son-las-estaciones-de-metro-con-mayorafluencia-el-mercurio/.

Herrero, R. (2009). Sistemas de Ventilación en Ferrocarriles Metropolitanos: Panorámica y Estrategias de Diseño. Proyecto fin de Carrera - Ingeniería Industrial. Universidad Carlos III de Madrid, Madrid, España.

Hoyt, T., Schiavon, S., Piccioli, A., Cheung, T., Moon, D. y Steinfeld, K. (2017). CBE Thermal Comfort Tool. Center for the Built Environment. Recuperado de http://comfort.cbe.berkeley.edu/EN.

Instalan megaventiladores para disminuir el calor en estaciones de Metro (2010). La Tercera. Recuperado de https://www.latercera. com/noticia/instalan-megaventiladores-para-disminuir-el-calor-enestaciones-de-metro/.

Instituto Nacional de Estadísticas (INE) (2019). Índices de Remuneraciones y Costo de Mano de Obra - IR ICMO. Instituto Nacional de Estadísticas Chile. Recuperado de https://www.ine.cl/ estadisticas/laborales/ir-icmo.

Liencura, J. (2019). ¡Estamos fritos! Hasta $38^{\circ}$ deben soportar pasajeros del transporte público en Santiago. Publimetro Chile. Recuperado de https://www.publimetro.cl/cl/noticias/2019/01/04/ hasta-38oc-soportar-pasajeros-transantiago-metro.html.

Metro S.A. (2007). Anexos Estadísticos 2007. Santiago.

Metro S.A. (2010). Metro implementa mega ventiladores para disminuir calor en estaciones. Web Metro de Santiago. Recuperado de https://www.metro.cl/noticias/detalle/923.

Metro S.A. (2013). Metro inicia plan de verano 2013-2014. Web Metro de Santiago. Recuperado de https://www.metro.cl/noticias/ detalle/1339.

Metro S.A. (2015). Especificaciones técnicas. Servicio de mantenimiento de sistemas de ventilación industrial y nebulizadores en estaciones de Metro S.A. Santiago.

ONDAC. Manual de Costos: Materiales y Actividades para la Construcción. Santiago: ONDAC, 2018.

The Norwegian Metereological Institute (2016). WeatherSpark. Recuperado de https://weatherspark. com/\#!dashboard;loc=-33.4184,-70.6020. 